\title{
Changes in intraocular pressure values measured with noncontact tonometer (NCT), ocular response analyzer (ORA) and corvis scheimpflug technology tonometer (CST) in the early phase after small incision lenticule extraction (SMILE)
}

Yang Shen ${ }^{1,2+}$, Xiangjian Su ${ }^{3+}$, Xiu Liu ${ }^{3}$, Huamao Miao ${ }^{1,2}$, Xuejun Fang ${ }^{3 *}$ and Xingtao Zhou ${ }^{1,2^{*}}$ (D)

\begin{abstract}
Background: Corneal biomechanical properties are always compromised after corneal refractive surgeries thus leading to underestimated intraocular pressure (IOP) that complicates the management of IOP. We investigated the changes in postoperative baseline of IOP values measured with noncontact tonometer (NCT), ocular response analyzer (ORA) and corvis scheimpflug technology (CST) in the early phase after small incision lenticule extraction (SMILE).

Methods: Twenty-two eyes (-6.76 $\pm 1.39 D)$ of 22 moderate and high myopes, $(28.36 \pm 7.14$ years, 12 male and 10 female) were involved in this prospective study. IOP values were measured using a non-contact tomometer (NCT-IOP), an ocular response analyzer (corneal-compensated IOP, IOPCC and Goldmann-correlated IOP, IOPg) and a Corvis scheimpflug technology tonometer (CST-IOP) preoperatively, at $20 \mathrm{~min}$ and $24 \mathrm{~h}$, postoperatively. Repeated measures analysis of variance (RM-ANOVA), Pearson's correlation analysis and multiple linear regression models (stepwise) were performed. Cut-off $P$ values were 0.05 .

Results: Except for IOPCC, NCT-IOP, IOPg, and CST-IOP values significantly decreased after SMILE procedure (All $P$ values $<0.05)$. $\Delta C C T$, as well as $\triangle \mathrm{MRSE}$ and $\Delta \mathrm{Km}$, did not significantly correlated with $\triangle N C T-I O P, \Delta I O P C C, \Delta I O P g$ or $\Delta$ CST-IOP, (all $P$ values $>0.05$ ). Multiple linear regression models (stepwise) showed that the practical post-operative IOP value was the main predictor of the theoretical post-operative NCT-IOP, IOPCC and IOPg values (all $P$ values $<0.001$ ). The postoperative applanation time 1 ( $A T 1$ ) value $(B=8.079, t=4.866, P<0.001)$, preoperative central corneal thickness $(C C T)$ value $(B=0.035, t=2.732, P=0.014)$ and postoperative peak distance $(P D)$ value $(B=0.515$, $\mathrm{t}=2.176, P=0.043$ ) were the main predictors of the theoretical post-operative CST-IOP value.

(Continued on next page)
\end{abstract}

\footnotetext{
* Correspondence: fangxuejun@vip.163.com; doctzhouxingtao@163.com

${ }^{\dagger}$ Equal contributors

${ }^{3}$ Shenyang Aier Eye Hospital, 11 Shiyiwei Road, Shenyang, Liaoning Province

110000, China

${ }^{1}$ Key Lab of Myopia, Ministry of Health, P.R. China, 19 Baoqing Road,

Shanghai 200031, China

Full list of author information is available at the end of the article
} 
(Continued from previous page)

Conclusions: IOP values are underestimated when assessed after SMILE by using NCT-IOP, IOPg and CST-IOP. The practical postoperative IOPCC value and theoretical post-operative CST-IOP value may be more preferable for IOP assessment in the early phase after SMILE.

Trial registration: Current Controlled Trials ChiCTRONRC13003114. Retrospectively registered 17 March 2013

Keywords: Intraocular pressure, Corneal biomechanical property, Corneal deformation parameter, Small incision lenticule extraction, Ocular response analyzer, Corvis scheimpflug technology tonometer

\section{Background}

With the booming popularity of refractive surgeries, nowadays, intraocular pressure (IOP) management is not only essential for patients with glaucoma but also for those myopes who underwent refractive surgeries as long-term use of topical steroid may cause steroid-induced ocular hypertension, and primary open-angle glaucoma is a common complication accompanying myopia $[1,2]$. However, corneal refractive surgeries remove corneal tissue, modify corneal shape and compromise corneal biomechanical properties thus leading to underestimated IOP values [3] and obscure the diagnosis of ocular hypertension. Noncontact tonometer (NCT), ocular response analyzer (ORA) and corvis scheimpflug technology tonometer (CST) are three most commonly employed instruments for clinical IOP assessment. Goldmann applanation tonometer is the gold standard method for IOP assessment; nonetheless, its accuracy still depends on central corneal thickness (CCT), anterior corneal curvature and other potential factors that may affect corneal biomechanical properties [4-6]. The permanent corneal flap and the incomplete Bowman's layer, caused by laserassisted in situ keratomileusis (LASIK) or surface ablation techniques, are another two major factors that weaken corneal stiffness and affect postoperative IOP assessment $[7,8]$.

Previously, large quantities of formulas have been raised to correct IOP values following corneal refractive surgeries [9-11]. However, various confounding factors including surgical designs (i.e., flap thickness, residual stromal bed thickness, optic zone diameter and ablation depth), individual differences (i.e., age, gender, race, refractions, corneal curvature corneal hydration and postoperative wound healing response) [12] and long-term postoperative topical steroid usage make these formulas widely divergent.

Femtosecond laser small incision lenticule extraction (SMILE) is a flapless and minimally invasive corneal refractive surgery $[3,13]$. With a refractive stromal lenticule extracted from a $2 \mathrm{~mm}$-long side-cut, the integrity of corneal structure (including the Bowman's layer) and corneal biomechanical properties are maximally maintained [14]. Technically, SMILE procedure only modifies corneal curvature and corneal thickness.
To minimize the interference of those confounding factors, in the present study, IOP values were obtained preoperatively, at $20 \mathrm{~min}$ postoperatively and at $24 \mathrm{~h}$ post-operatively by using the three frequently employed noncontact tonometers. We hypothesis the theoretical post-operative IOP values should be similar with the preoperative values. The gap between preoperative and postoperative IOP values should be dominantly caused by the surgery itself. As IOP values are always underestimated following corneal refractive surgeries [15], to investigate and establish a statistical model for compensating the gap between the pre-operative and the postoperative IOP values by involving corneal biomechanical parameters should be meaningful for clinical IOP management.

\section{Methods}

This prospective study was registered in Chinese Clinical Trial Registry (Trial registration: Current Controlled Trials ChiCTRONRC13003114. Retrospectively registered 17 March 2013), approved by ethics committee of Eye and ENT Hospital, Fudan University and was conducted with due regard to the tenets of the Declaration of Helsinki. Written informed consent was obtained from the participants after explanation of procedure was given.

\section{Participants}

Twenty-two moderate and high myopes $(28.4 \pm 7.1$ years, 12 male and 10 female) were recruited in this prospective study at the Department of Ophthalmology, Eye and ENT Hospital, Fudan University. All the right eyes $(-6.76 \pm 1.39 \mathrm{D})$ were analyzed.

\section{Pre-operative examinations}

Each participant underwent routine preoperative ophthalmologic examinations, including uncorrected distance visual acuity (UDVA), manifest refraction, best-corrected distance visual acuity (BDVA), slit lamp examination and fundus examination. Corneal topography was measured with a three-dimensional anterior segment analyzer (Pentacam HR, Typ70900, Oculus Optikgeräte GmbH, Wetzlar, Germany). The mean anterior corneal curvature $(\mathrm{Km})$ and CCT were recorded. Preoperative IOP was measured with a noncontact tonometer (NCT, TX-20 Full Auto Tonometers, Canon, Japan), an ocular response 
analyzer (ORA, Reichert Inc, Depew, New York, USA) and a corvis scheimpflug technology tonometer (CST, Oculus Optikgeräte GmbH, Wetzlar, Germany). The sequence of measurement using these three instruments was arranged randomly. All the IOP measurements were obtained in a sitting position. NCT continuously obtained three valid readings and the mean value was calculated automatically. ORA provided values of cornealcompensated IOP (IOPcc), Goldmann-correlated IOP (IOPg), corneal hysteresis $(\mathrm{CH})$ and corneal resistance factor (CRF). Four measurements were obtained in each eye and the one with the highest waveform score (WS) was recorded. CST-IOP and corneal deformation parameters were measured using CST. The measurement with an "OK" in Quality Specification (QS) was recorded [13].

\section{Surgical technique}

SMILE procedures were performed under topical anaesthesia using three drops of $0.4 \%$ Oxybuprocaine Hydrochloride (Santen Pharmaceutical Co., Ltd., Japan). One surgeon (ZXT) performed all the procedures with the VisuMax femtosecond laser system (Carl Zeiss Meditec AG, Germany). The intended thickness of the upper tissue arcade was set $120 \mu \mathrm{m}$, and its diameter was $7.5 \mathrm{~mm}$. The diameter of the lenticule was $6.7 \mathrm{~mm}$. The side cuts were set $90^{\circ}$ apart at a width of $2 \mathrm{~mm}$. The refractive lenticule of the intra-stromal corneal tissue was extracted through the side-cut opening using a modified serrated McPherson forceps (Geuder, GmbH, Heidelberg, Germany) [3].

Post-operative examinations and topical eye drops usage UDVA, manifest refraction, BDVA, slit lamp examination, NCT-IOP, IOPcc, IOPg, CST-IOP were measured again at postoperative $20 \mathrm{~min}$ and postoperative $24 \mathrm{~h}$. Corneal topography was measured again at $24 \mathrm{~h}$ postoperatively. Topical steroid (fluorometholone 0.1\%; Santen Pharmaceutical Co., Ltd.), topical antibiotics (ofloxacin ophthalmic solutions 0.5\%; Santen Pharmaceutical Co., Ltd.) and artificial tear (hypromellose 2910, dextran 70, glycerol eye drops; Alcon Laboratories, Inc., Fort Worth,
TX) were used at 3-h intervals after SMILE procedure. At the first day post-operatively, topical steroid, topical antibiotics and artificial tear were employed for 4 times per day [13].

\section{Data analysis and statistical evaluation}

Statistical analysis was performed using SPSS 19 (SPSS Inc., IBM, USA). All the data were tested for normality using the Kolmogorov-Smirnov test. Repeated measures analysis of variance (RM-ANOVA) with LSD post hoc comparisons was performed to evaluate the changes in NCT-IOP, IOPcc, IOPg and CST-IOP over time. Pearson's correlation analysis was applied to detect the potential correlations between these variables. Stepwise multiple linear regression model analysis was performed to predict theoretical post-operative IOP values. To minimize the effect of corneal epithelium edema, the IOP value obtained at $20 \mathrm{~min}$ post-operatively was excluded from the analysis. Cut-off $\mathrm{P}$ values were 0.05 .

\section{Results}

All surgical procedures were successful and uneventful. The stromal layers of all the corneas were clear. Although mild epithelial edema could be observed in some cases by using a silt-lamp bio-microscopy at $20 \mathrm{~min}$ postoperatively but this sign disappeared at $24 \mathrm{~h}$ postoperatively. The main demographic and topographic data were shown in the Table 1.

\section{IOP measurements}

As demonstrated in the Table 2, the measurements of NCT-IOP, IOPg, and CST-IOP significantly decreased after SMILE procedure (All $P$ values $<0.05$ ). Fisher's least significant difference (LSD) post hoc comparisons (Fig. 1) revealed that at $20 \mathrm{~min}$ postoperatively, the mean values of NCT-IOP (post hoc $P<0.001$ ), IOPg (post hoc $P<0.001$ ) and CST-IOP (post hoc $P<0.001$ ) were all decreased dramatically when compared with the pre-operative values, but all of the values kept stable in

Table 1 The main demographic and topographic data $(n=22)$

\begin{tabular}{|c|c|c|c|c|c|c|}
\hline \multirow[t]{2}{*}{ Variables } & \multicolumn{2}{|l|}{ Pre-operative } & \multicolumn{2}{|c|}{ Postoperative $24 \mathrm{~h}$} & \multirow[t]{2}{*}{ Fvalue $^{a}$} & \multirow[t]{2}{*}{$P$ value } \\
\hline & Mean \pm SD & Range & Mean \pm SD & Range & & \\
\hline Age (year) & $28.4 \pm 7.1$ & 18 to 42 & $28.4 \pm 7.1$ & 18 to 42 & - & - \\
\hline MRSE (D) & $-6.76 \pm 1.39$ & -10.00 to -4.13 & $-0.22 \pm 0.48$ & -1.38 to 0.75 & 508.580 & $<0.001^{b}$ \\
\hline K1 (D) & $43.23 \pm 1.40$ & 40.1 to 45.2 & $38.35 \pm 2.12$ & 32.3 to 40.9 & 510.718 & $<0.001^{\mathrm{b}}$ \\
\hline K2 (D) & $44.56 \pm 1.84$ & 41.0 to 47.6 & $39.03 \pm 2.23$ & 32.7 to 42.3 & 557.309 & $<0.001^{b}$ \\
\hline $\mathrm{Km}(\mathrm{D})$ & $43.88 \pm 1.54$ & 40.6 to 46.4 & $38.69 \pm 2.15$ & 32.5 to 41.6 & 622.613 & $<0.001^{\mathrm{b}}$ \\
\hline Pentacam-CCT $(\mu \mathrm{m})$ & $546.6 \pm 23.4$ & 515 to 592 & $431.9 \pm 28.0$ & 399 to 501 & 521.421 & $<0.001^{\mathrm{b}}$ \\
\hline
\end{tabular}

MRSE manifest refraction spherical equivalent, $D$ diopter, $K 1$ flat curvature power, $K 2$ flat curvature power, Km mean curvature power, $C C T$ central corneal thickness ${ }^{a}$ Repeated measures analysis of variance (RM-ANOVA)

bSignificant difference was detected 
Table 2 Changes in IOP measurements $(n=22)$

\begin{tabular}{|c|c|c|c|c|c|c|c|c|}
\hline \multirow[t]{2}{*}{ Variables } & \multicolumn{2}{|c|}{ Pre-operative } & \multicolumn{2}{|c|}{ Postoperative 20 min } & \multicolumn{2}{|c|}{ Postoperative $24 \mathrm{~h}$} & \multirow[t]{2}{*}{$F$ value $^{a}$} & \multirow[t]{2}{*}{$P$ value } \\
\hline & Mean \pm SD & Range & Mean \pm SD & Range & Mean \pm SD & Range & & \\
\hline NCT-IOP (mmHg) & $15.04 \pm 2.91$ & 11.1 to 20.9 & $9.19 \pm 2.52$ & 4.6 to 15.2 & $9.70 \pm 2.95$ & 5.8 to 17.2 & 81.173 & $<0.001^{\mathrm{b}}$ \\
\hline IOPcc (mmHg) & $14.99 \pm 2.46$ & 10.2 to 19.0 & $16.65 \pm 4.29$ & 12.1 to 29.4 & $14.01 \pm 3.10$ & 6.8 to 20.3 & 4.975 & $0.030^{\mathrm{b}}$ \\
\hline $\mathrm{IOPg}(\mathrm{mmHg})$ & $15.10 \pm 3.21$ & 9.3 to 21.9 & $11.20 \pm 3.38$ & 4.7 to 18.2 & $9.52 \pm 2.85$ & 4.5 to 15.9 & 40.128 & $<0.001^{b}$ \\
\hline CST-IOP (mmHg) & $17.74 \pm 2.16$ & 13.0 to 23.0 & $14.29 \pm 2.09$ & 10.0 to 17.5 & $14.57 \pm 1.58$ & 10.5 to 18.0 & 31.886 & $<0.001^{\mathrm{b}}$ \\
\hline
\end{tabular}

IOPcc corneal-compensated IOP, IOPg Goldmann-correlated IOP

${ }^{a}$ Repeated measures analysis of variance (RM-ANOVA)

${ }^{\text {b}}$ Significant difference was detected over time

the next $24 \mathrm{~h}$ (post hoc $P=0.365$, post hoc $P=0.050$ and post hoc $P=0.585$, respectively). The mean values of IOPcc slightly increased at the 20-min mark (post hoc $P=0.056)$, but then deceased significantly at the $24-\mathrm{h}$ mark $(P=0.028)$ however, no significant difference was detected between the IOPcc values obtained before and $24 \mathrm{~h}$ after SMILE (post hoc $P=0.051$ ).

\section{Changes in corneal biomechanical and deformation parameters}

The definition of each deformation parameter was listed in the Table $3[3,13,16]$. As shown in the Table 4, the mean values of corneal hysteresis $(\mathrm{CH})$, corneal resistance factor (CRF), AT1, AV1, AV2, Radius, DA all changed significantly after SMILE procedure (All $P$ values $<0.001$ ). $\mathrm{CH}$ (post hoc $P<0.001$ ), CRF (post hoc $P<0.001$ ), AT1 (post hoc $P<0.001$ ), AV1 (post hoc $P=0.007$ ), AV2 (post hoc $P=0.016$ ) and Radius (post hoc $P=0.001$ ) decreased but DA increased remarkably (post hoc $P<0.001$ ) at 20 min postoperatively. While the remaining parameters in the Table 4 all kept unchanged (All $P$ values $>0.05$ ). Expect for the mean value of $\mathrm{CH}$, which kept decreasing at $24 \mathrm{~h}$ postoperatively (post hoc $P=0.025$ ), CRF, AT1, AV1, AV2, Radius and DA all remained stable at 24-h mark (All post hoc $P$ values $>0.05$ ).

\section{Correlations}

Pearson's correlation analysis showed that neither $\triangle \mathrm{NCT}$ IOP, $\Delta$ IOPcc, $\Delta$ IOPg nor $\Delta$ CST-IOP (" $\Delta$ " refers to the difference between the value obtained preoperatively and at $24 \mathrm{~h}$ postoperatively) significantly correlated with $\triangle \mathrm{CCT}, \triangle \mathrm{MRSE}$ or $\Delta \mathrm{Km}$ (all $P$ values $>0.05$ ) But the postoperative CCT value measured with CST (CST-CCT) significantly correlated with $\mathrm{CH}(\mathrm{R}=0.511, P=0.015)$ and $\mathrm{CRF}(\mathrm{R}=0.674, P=0.001)$.

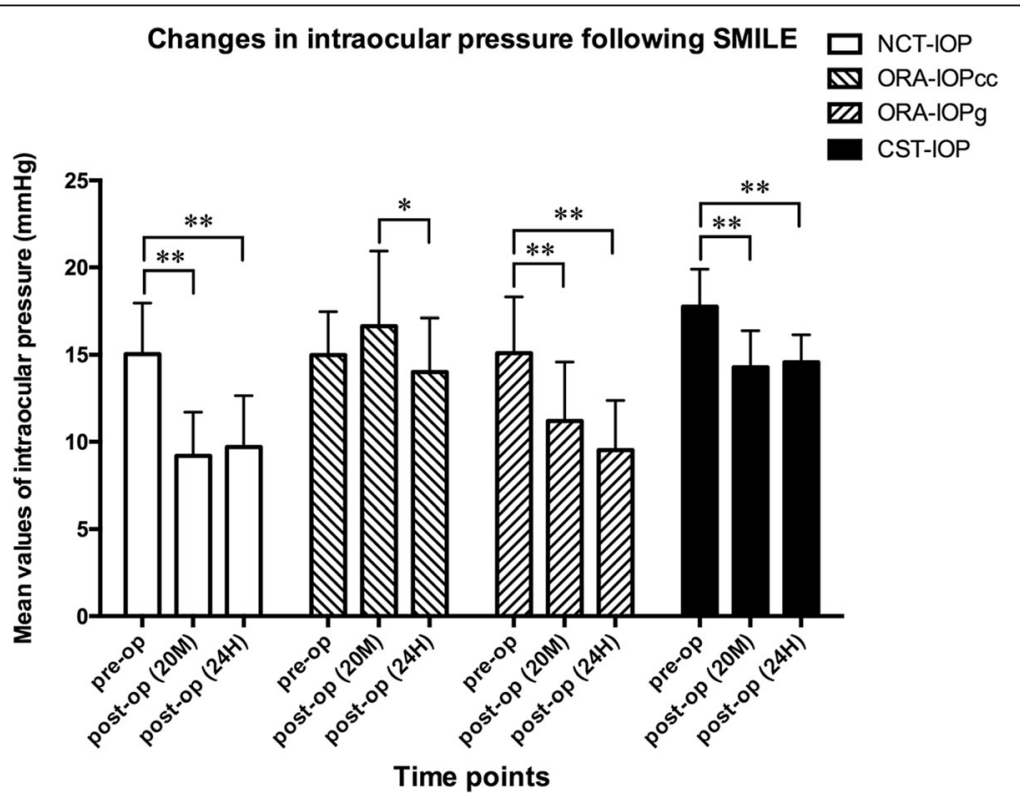

Fig. 1 Changes in intraocular pressure following SMILE obtained by, NCT (NCT-IOP), ORA(ORA-IOPCC and ORA-IOPg) and CST (CST-IOP). Pre-op= postoperative; Post-op = postoperative; $20 \mathrm{M}=20 \mathrm{~min} ; 24 \mathrm{H}=24 \mathrm{~h}$. " $*$ " refers to Fisher's least significant difference (LSD) post hoc $P$ value $<0.05$; " ${ }^{* * * \prime \prime}$ refers to $L S D$ post hoc $P$ value $<0.01$ 
Table 3 Abbreviations for corneal deformation parameters

\begin{tabular}{ll}
\hline Abbreviation & Definition \\
\hline AT1 & $\begin{array}{l}\text { Applination Time (time 1): the duration from the initiation } \\
\text { to the moment that a cornea just deformed for the first } \\
\text { time }\end{array}$ \\
ATh & $\begin{array}{l}\text { Applination Time (hightest concavity): the duration from } \\
\text { the initiation to the moment that a cornea is depressed } \\
\text { to the highest concavity }\end{array}$ \\
AT2 & $\begin{array}{l}\text { Applination Time (time 2): the duration from the initiation } \\
\text { to the moment that a corneal deformation just } \\
\text { completely resumed }\end{array}$ \\
AL1 & $\begin{array}{l}\text { Applination length (time 1): the cord length recorded at } \\
\text { the moment that a cornea just deformed for the first } \\
\text { time }\end{array}$ \\
AL2 & $\begin{array}{l}\text { Applination length (time 2): the cord length recorded at } \\
\text { the moment that a corneal deformation just completely } \\
\text { resumed }\end{array}$ \\
AV1 & $\begin{array}{l}\text { Applination velocity (time 1): the instantaneous velocity } \\
\text { recorded when a cornea just deformed }\end{array}$ \\
AV2 & $\begin{array}{l}\text { Applination velocity (time 2): the instantaneous velocity } \\
\text { recorded when a cornea just completely resumed }\end{array}$ \\
Radius & $\begin{array}{l}\text { Radius: the corneal radius obtained when a cornea is } \\
\text { depressed to the highest concavity }\end{array}$ \\
PD & $\begin{array}{l}\text { Peak Distance: the distance between the two corneal } \\
\text { peaks recorded when a cornea is depressed to the } \\
\text { highest concavity } \\
\text { Deformation Amplitude: the maximum amplitude of } \\
\text { corneal deformation recorded when a cornea is } \\
\text { depressed to the highest concavity }\end{array}$ \\
&
\end{tabular}

\section{Stepwise multiple linear regression models}

The Table 5 demonstrated the statistically significant stepwise linear multiple regression models for predicting the theoretical postoperative values of NCT-IOP (Adjusted $\mathrm{R}^{2}=0.400, \mathrm{~F}=15.000, \mathrm{P}=0.001$ ), IOPcc (Adjusted $\mathrm{R}^{2}=$ $0.472, \mathrm{~F}=19.755, P<0.001$ ), IOPg (Adjusted $\mathrm{R}^{2}=0.542$, $\mathrm{F}=25.850, P<0.001$ ) and CST-IOP (Adjusted $\mathrm{R}^{2}=0.596$, $\mathrm{F}=11.336, P<0.001)$.

The practical post-operative NCT-IOP value was the main predictor of the theoretical post-operative NCTIOP value $(B=0.646, t=3.873, P=0.001)$, but the theoretical post-operative NCT-IOP value did not associated with age, preoperative $\mathrm{CCT}$, postoperative $\mathrm{CCT}$, corneal curvature or $\triangle$ MRSE (All $P$ values $>0.05$ ).

For IOPcc and IOPg, the practical post-operative IOPcc and IOPg values were the main predictors $(B=0.558$, $\mathrm{t}=4.445, P<0.001 ; \mathrm{B}=0.848, \mathrm{t}=5.084, P<0.001$, respectively) for predicting theoretical post-operative IOPcc and IOPg value. But both the theoretical postoperative IOPcC and IOPg values did not associated with age, preoperative CCT, postoperative $\mathrm{CCT}$, postoperative $\mathrm{CH}$, postoperative $\mathrm{CRF}$, corneal curvature or $\triangle$ MRSE (All $P$ values $>0.05$ ).

For CST-IOP, the postoperative AT1 value $(\mathrm{B}=8.079$, $\mathrm{t}=4.866, P<0.001)$, preoperative $\mathrm{CCT}$ value $(\mathrm{B}=0.035$, $\mathrm{t}=2.732, P=0.014)$ and postoperative $\mathrm{PD}$ value $(\mathrm{B}=0.515$, $\mathrm{t}=2.176, P=0.043)$ were the main predictors of the theoretical post-operative CST-IOP value. But the theoretical post-operative CST-IOP value did not associated with age, postoperative CCT, corneal curvature, $\triangle \mathrm{MRSE}$ or other postoperative CST parameters (All $P$ values $>0.05$ ).

Table 4 Changes in corneal biomechanical and deformation parameters $(n=22)$

\begin{tabular}{|c|c|c|c|c|c|c|c|c|}
\hline \multirow[t]{2}{*}{ Variables } & \multicolumn{2}{|l|}{ Pre-operative } & \multicolumn{2}{|c|}{ Postoperative $20 \mathrm{~min}$} & \multicolumn{2}{|c|}{ Postoperative $24 \mathrm{~h}$} & \multirow[t]{2}{*}{ F value ${ }^{a}$} & \multirow[t]{2}{*}{$P$ value } \\
\hline & Mean \pm SD & Range & Mean \pm SD & Range & Mean \pm SD & Range & & \\
\hline $\mathrm{CH}(\mathrm{mmHg})$ & $11.05 \pm 1.81$ & 8.7 to 16.7 & $6.82 \pm 0.98$ & 5.3 to 8.4 & $7.49 \pm 1.32$ & 5.6 to 11.0 & 90.283 & $<0.001^{b}$ \\
\hline $\mathrm{CRF}(\mathrm{mmHg})$ & $10.84 \pm 2.20$ & 7.1 to 17.3 & $6.07 \pm 1.26$ & 2.9 to 9.3 & $6.09 \pm 1.27$ & 4.1 to 9.1 & 131.239 & $<0.001^{b}$ \\
\hline CST-CCT $(\mu \mathrm{m})$ & $545.8 \pm 24.8$ & 515.0 to 618.0 & $469.7 \pm 46.4$ & 389 to 580 & $440.9 \pm 29.5$ & 407 to 522 & 136.093 & $<0.001^{\mathrm{b}}$ \\
\hline AT1 (ms) & $7.28 \pm 0.26$ & 6.71 to 7.97 & $6.91 \pm 0.23$ & 6.52 to 7.32 & $6.90 \pm 0.18$ & 6.54 to 7.37 & 36.484 & $<0.001^{\text {b }}$ \\
\hline ATh (ms) & $16.94 \pm 0.53$ & 16.17 to 17.79 & $16.77 \pm 0.86$ & 14.32 to 18.02 & $16.94 \pm 0.63$ & 15.71 to 18.02 & 0.465 & 0.631 \\
\hline AT2 (ms) & $21.64 \pm 1.29$ & 16.89 to 22.82 & $22.13 \pm 0.41$ & 21.36 to 22.86 & $22.17 \pm 0.29$ & 21.61 to 22.87 & 3.042 & 0.089 \\
\hline AL1 (mm) & $1.78 \pm 0.04$ & 1.71 to 1.87 & $1.72 \pm 0.17$ & 1.26 to 1.92 & $1.74 \pm 0.20$ & 1.19 to 1.94 & 0.798 & 0.429 \\
\hline $\mathrm{AL} 2(\mathrm{~mm})$ & $1.49 \pm 0.39$ & 0.44 to 2.00 & $1.35 \pm 0.44$ & 0.73 to 2.00 & $1.22 \pm 0.41$ & 0.73 to 1.89 & 2.281 & 0.131 \\
\hline $\mathrm{AV} 1(\mathrm{~m} / \mathrm{s})$ & $0.16 \pm 0.02$ & 0.09 to 0.22 & $0.14 \pm 0.02$ & 0.08 to 0.19 & $0.15 \pm 0.02$ & 0.11 to 0.20 & 5.528 & $0.007^{b}$ \\
\hline AV2 (m/s) & $-0.44 \pm 0.14$ & -0.92 to -0.20 & $-0.56 \pm 0.13$ & -0.75 to -0.33 & $-0.61 \pm 0.16$ & -1.11 to -0.33 & 8.910 & $0.001^{b}$ \\
\hline $\mathrm{PD}(\mathrm{mm})$ & $4.27 \pm 1.19$ & 2.36 to 5.43 & $4.51 \pm 1.25$ & 2.62 to 6.19 & $4.53 \pm 1.27$ & 2.57 to 6.23 & 0.355 & 0.704 \\
\hline Radius (mm) & $6.97 \pm 1.46$ & 1.66 to 9.45 & $5.51 \pm 1.00$ & 1.78 to 6.88 & $5.69 \pm 0.54$ & 4.89 to 7.05 & 13.208 & $<0.001^{\mathrm{b}}$ \\
\hline $\mathrm{DA}(\mathrm{mm})$ & $1.09 \pm 0.09$ & 0.89 to 1.37 & $1.17 \pm 0.10$ & 1.03 to 1.43 & $1.14 \pm 0.07$ & 0.99 to 1.34 & 10.100 & $<0.001^{\mathrm{b}}$ \\
\hline
\end{tabular}

MRSE manifest refraction spherical equivalent, $D$ diopter, $C H$ corneal hysteresis, $C R F$ corneal resistance factor, $C C T$ central corneal thickness, $A T 1$ applanation time $1, A T h$ applanation time at the highest concavity; $A T 2$ applanation time $2, A L 1$ applanation length $1 ; A L 2$ applanation length $2, A V 1$ applanation velocity $1, A V 2$ applanation velocity 2, $P D$ peak distance, $D A$ deformation amplitude

${ }^{a}$ Repeated measures analysis of variance (RM-ANOVA)

${ }^{b}$ Significant difference was detected over time 
Table 5 The stepwise multiple linear regression models for predicting theoretical post-op IOP values $(n=22)$

\begin{tabular}{|c|c|c|c|c|c|c|c|c|c|c|}
\hline $\begin{array}{l}\text { Dependent } \\
\text { Variables } \\
\end{array}$ & Main Predictors & $\mathrm{B}^{\mathrm{a}}$ & $\mathrm{SE}^{\mathrm{b}}$ & $t^{c}$ & Sig. & $\beta^{d}$ & Regression Equation & Adjusted $\mathrm{R}^{2}$ & $\mathrm{~F}^{\mathrm{e}}$ & Sig. \\
\hline \multirow[t]{2}{*}{ Pre-op NCT-IOP } & $\begin{array}{l}\text { Practical postop } \\
\text { NCT-IOP }\end{array}$ & 0.646 & 0.167 & 3.873 & $<0.001$ & 0.655 & \multirow{2}{*}{$\begin{array}{l}\text { Theoretical post-op NCT-IOP } \\
(\mathrm{mmHg})=0.646 \times \text { Practical } \\
\text { post-op NCT-IOP }(\mathrm{mmHg}) \\
+8.774(\mathrm{mmHg})\end{array}$} & \multirow[t]{2}{*}{0.400} & \multirow[t]{2}{*}{15.000} & \multirow[t]{2}{*}{$<0.001$} \\
\hline & Constant & 8.774 & 1.688 & 5.198 & 0.001 & - & & & & \\
\hline \multirow[t]{2}{*}{ Pre-op ORAIOPcC } & $\begin{array}{l}\text { Practical postop } \\
\text { IOPcC }\end{array}$ & 0.558 & 0.126 & 4.445 & $<0.001$ & 0.705 & \multirow{2}{*}{$\begin{array}{l}\text { Theoretical post-op IOPcc }(\mathrm{mmHg}) \\
=0.558 \times \text { practical postoperative } \\
\text { IOPcc }(\mathrm{mmHg})+7.166(\mathrm{mmHg})\end{array}$} & \multirow[t]{2}{*}{0.472} & \multirow[t]{2}{*}{19.755} & \multirow[t]{2}{*}{$<0.001$} \\
\hline & Constant & 7.166 & 1.800 & 3.981 & 0.001 & - & & & & \\
\hline \multirow[t]{2}{*}{ Pre-op ORAIOPg } & $\begin{array}{l}\text { Practical } \\
\text { postoplOPg }\end{array}$ & 0.848 & 0.167 & 5.084 & $<0.001$ & 0.751 & \multirow{2}{*}{$\begin{array}{l}\text { Theoretical post-op IOPg }(\mathrm{mmHg}) \\
=0.848 \times \text { practical postoperative } \\
\mathrm{IOPg}(\mathrm{mmHg})+7.024(\mathrm{mmHg})\end{array}$} & \multirow[t]{2}{*}{0.542} & \multirow[t]{2}{*}{25.850} & \multirow[t]{2}{*}{$<0.001$} \\
\hline & Constant & 7.024 & 1.654 & 4.247 & $<0.001$ & - & & & & \\
\hline \multirow[t]{4}{*}{ Pre-op CST-IOP } & Post-op AT1 & 8.079 & 1.660 & 4.866 & $<0.001$ & 0.680 & \multirow{4}{*}{$\begin{array}{l}\text { Theoretical post-op CST-IOP } \\
(\mathrm{mmHg})=8.079 \times \text { post-op } \\
\text { AT1 }(\mathrm{ms})+0.035 \times \text { pre-op } \\
\text { CCT }(\mu \mathrm{m})+0.515 \times \text { post-op } \\
\text { PD }(\mathrm{mm})-59.47 \mathrm{mmHg}\end{array}$} & \multirow[t]{4}{*}{0.596} & \multirow[t]{4}{*}{11.336} & \multirow[t]{4}{*}{$<0.001$} \\
\hline & Pre-op CCT & 0.035 & 0.013 & 2.732 & 0.014 & 0.379 & & & & \\
\hline & Post-op PD & 0.515 & 0.237 & 2.176 & 0.043 & 0.304 & & & & \\
\hline & Constant & -59.47 & 13.524 & -4.397 & $<0.001$ & - & & & & \\
\hline
\end{tabular}

Pre-op pre-operative, Post-op post-operative, AT1 applanation time 1, CCT central corneal thickness, PDpeak distance, Sig. Significance

aunstandardized Coefficients

${ }^{\mathrm{b}}$ Standard Error of Unstandardized Coefficients

'Unstandardized Coefficients/Standard Error

dStandardized Coefficients (Beta)

${ }^{\mathrm{e}}$ Multiple Linear Regression Model (Stepwise)

\section{Discussion}

Corneal refractive surgeries compromise corneal mechanical strength, thus leading to underestimated IOP, which may obscure the diagnosis of steroid-induced glaucoma or open-angle glaucoma during postoperative follow-ups $[17,18]$.

In the present study, the mean values of NCT-IOP, IOPcc, IOPg and CST-IOP significantly deceased at $24 \mathrm{~h}$ postoperatively. Post-operative CCT significantly correlated with $\mathrm{CH}$ and $\mathrm{CRF}$, but $\triangle \mathrm{CCT}$, as well as $\triangle \mathrm{MRSE}$ and $\Delta \mathrm{Km}$, did not correlated with $\triangle \mathrm{NCT}$-IOP, $\triangle \mathrm{IOPcc}$, $\triangle \mathrm{IOPg}$ or $\triangle \mathrm{CST}-\mathrm{IOP}$, indicating that $\triangle \mathrm{CCT}, \triangle \mathrm{MRSE}$ and corneal curvature may not be the main factors affecting IOP measurements. $\mathrm{CH}$ and CRF reflect the characters of force absorption and the resistance of the cornea, respectively. They are both dependent to corneal thickness [19]. Vestergaard AH, et al. [20] reported $\mathrm{CH}$ and CRF still significantly correlated with CCT after SMILE procedure, while Shah S [15] reported that $\Delta \mathrm{CH}$ and $\triangle \mathrm{CRF}$ did not correlated with $\triangle \mathrm{CCT}$ after corneal refractive surgeries. A possible explanation is that comparing with the removed corneal tissue, the residual cornea contributed much more effect in maintaining the entire corneal biomechanical strength.

The stepwise multiple linear regression model analysis revealed that the practical post-operative IOP values obtained using NCT and ORA were the main predictors of the theoretical post-operative IOP values (Pre-operative IOP values). The models explained 40.0, 47.2 and 54.2\% of the variance assessed using NCT-IOP, IOPcc and
IOPg respectively. For CST, the postoperative AT1 value, preoperative CCT value and postoperative PD value were the main predictors of the theoretical post-operative CST-IOP value. CST-IOP model explained $59.6 \%$ of the variance.

We found it is interesting that the change in CCT seems to be independent of the change in IOP value after SMILE procedure as neither $\triangle \mathrm{CCT}$ value was correlated with $\triangle \mathrm{NCT}$-IOP, $\triangle \mathrm{IOP} C \mathrm{IIOPg}$ or $\triangle \mathrm{CST}$-IOP nor CCT was a predictor of theoretical post-operative IOP value. So far, various instruments including NCT [21], ORA [22], CST, Goldmann applanation tonometry (GAT) and dynamic contour tonometry (DCT) [23] have been employed to investigate the changes in IOP values after LASIK. Cheng AC, et al. [21] reported the preoperative NCT-IOP significantly correlated with the postoperative one after LASIK. Moreover, postoperative CCT and ablation depth were included into their model, which was different from ours. Chen $\mathrm{S}$ and his colleagues [22] studied the changes in ORA parameters after myopic LASIK. They found that $\triangle \mathrm{IOPg}$ was positively correlated with $\triangle \mathrm{CCT}$, but $\triangle \mathrm{IOPcc}$ was not. In addition, they found ablation depth was correlated with $\triangle \mathrm{CRF}$ and $\triangle \mathrm{CH}$. It is also reported that CST and GAT would underestimate IOP following LASIK procedure [24]. The underlying reasons for these discrepancies may be the difference in surgical techniques and their efforts on corneal biomechanical structure. During LASIK procedure, stromal flap creation cuts almost all the collagen fibers in the anterior stroma of a cornea and compromised 
the integrality of the Bowman's layer, moreover, excimer laser ablated the stromal tissue, which contributes most of the biomechanics of the entire cornea. So the residual stromal bed undertakes the main role to maintain the corneal shape and biomechanical stability, in addition, the more corneal tissue removed, the lower the postoperative IOP value will be. However, SMILE procedure neither creates a stromal flap nor ablates Bowman's layer and the anterior stroma. As the corneal collagen fibers in the anterior stromal layer is much compact than that in the middle or posterior layer [25], most of the corneal biomechanical properties are remained. Reinstein DZ, et al. [14] developed a mathematical model to estimate the postoperative stromal tensile strength following SMILE, PRK and LASIK. They found that SMILE lenticule thickness could be approximately $100 \mu \mathrm{m}$ greater than the LASIK ablation depth, which is equivalent to approximately 7.75 diopters, and still have equivalent corneal strength. Wang D, et al. [26] found an interesting phenomenon that in myopia of $-6.00 \mathrm{D}$ or less, the $\Delta \mathrm{CH}$ and the $\triangle \mathrm{CRF}$ value between SMILE and LASIK were not significant. But in myopia greater than $-6.00 \mathrm{D}, \mathrm{CH}$ and CRF decreased more in LASIK than in SMILE. Another reason is that the NCT, ORA and CST may not be sensitive enough to detect the linear correlations between $\triangle \mathrm{IOP}$ and $\triangle \mathrm{CCT}$ as the residual cornea following SMILE contributes much more biochemical stability than the removed leuticule. We noticed that although the IOPcc values obtained at 20-min mark increased slightly but returned to pre-operative level at $24 \mathrm{~h}$ postoperatively, indicating corneal suction and surgical operation might also affect the postoperative IOP assessment [27]. As IOPcc is adjusted to account for $\mathrm{CH}$, which is significantly correlated with CCT value, the IOP gap can be compensated [28, 29]. Osman IM [16] reported similar findings, indicating that practical postoperative IOPcc value may be used to assess IOP after SMILE procedure.

The limitations of the present study are as follows. As the Goldmann applanation tonometer (GAT) IOP measurement has potential risk of infection, additionally, fluorescein sodium eye drops may infiltrate into the interlayer when GAT is employed for IOP assessment during the early post-operative phase, we were not able to obtain the GAT-IOP values. But the purpose of the study is to investigate the changes in IOP before and after SMILE with the same tonometer rather than to investigate the interrelations among the IOP values obtain with different instruments, GAT is not indispensable in the present study. As the biomechanical properties of the corneas underwent SMILE procedure may fluctuate during long-term follow-up, further studies are required to validate if the models were still effective in long-term outcomes of SMILE.

\section{Conclusions}

IOP values were underestimated when assessed by using NCT-IOP, IOPg and CST-IOPg after SMILE procedure. Both practical postoperative IOPcc values and theoretical post-operative CST-IOP values may be more preferable for IOP assessment or management following SMILE procedure.

\begin{abstract}
Abbreviations
AL 1: Applination length (time 1) is the cord length recorded at the moment that a cornea just deformed for the first time; AL2: Applination length (time 2 ) is the cord length recorded at the moment that a corneal deformation just completely resumed; AT1: Applination Time (time 1) is the duration from the initiation to the moment that a cornea just deformed for the first time; AT2: Applination Time (time 2) is the duration from the initiation to the moment that a corneal deformation just completely resumed;

ATh: Applination Time (hightest concavity) is the duration from the initiation to the moment that a cornea is depressed to the highest concavity; AV1: Applination velocity (time 1) is the instantaneous velocity recorded when a cornea just deformed; AV2: Applination velocity (time 2): the instantaneous velocity recorded when a cornea just completely resumed; DA: Deformation Amplitude is the maximum amplitude of corneal deformation recorded when a cornea is depressed to the highest concavity; PD: Peak distance is the distance between the two corneal peaks recorded when a cornea is depressed to the highest concavity; Radius: Is the corneal radius obtained when a cornea is depressed to the highest concavity
\end{abstract}

\section{Acknowledgments}

Not applicable.

\section{Funding}

(1) National Natural Science Foundation of China (Grant No.81570879) (2) Outstanding Academic Leaders Program of Shanghai Health System (Grant No. XBR2013098).

(3) Liaoning Province Science and Technology Project (Grant No.2013225303) The funders had no role in study design, data collection and analysis, decision to publish or preparation of the manuscript.

Availability of data and materials

Available upon request from the co-first authors Yang Shen and Xiangjian Su.

\section{Authors' contributions}

YS and XJS were the major contributors in writing the manuscript; YS, XJS and $X L$ collected the data. HMM analyzed and interpreted the data; XTZ and XJF designed the study; XTZ operated the surgeries. All authors read and approved the final manuscript.

\section{Competing interests}

The authors declare that they have no competing interests.

Consent for publication

Not applicable.

Ethics approval and consent to participate

This prospective study was registered in Chinese Clinical Trial Registry (Trial registration: Current Controlled Trials ChiCTRONRC13003114. Retrospectively registered 17 March 2013) website: http://www.chictr.org.cn/showproj.aspx? proj=6445), approved by ethics committee of Eye and ENT Hospital, Fudan University and was conducted with due regard to the tenets of the Declaration of Helsinki. Written informed consent was obtained from the participants after explanation of procedure was given.

\section{Author details}

${ }^{1}$ Key Lab of Myopia, Ministry of Health, P.R. China, 19 Baoqing Road, Shanghai 200031, China. ²Department of Ophthalmology, EYE \& ENT Hospital of Fudan University, Shanghai, China, 83 Fenyang Road, Shanghai 200031, China. ${ }^{3}$ Shenyang Aier Eye Hospital, 11 Shiyiwei Road, Shenyang, Liaoning Province 110000, China. 
Received: 9 August 2016 Accepted: 4 November 2016

Published online: 18 November 2016

\section{References}

1. Levinger E, Slomovic A, Bahar I, Slomovic AR. Diagnosis of steroid-induced elevated intraocular pressure and associated lamellar keratitis after laser in situ keratomileusis using optical coherence tomography. J Cataract Refract Surg. 2009;35:386-8.

2. Worley A, Grimmer-Somers K. Risk factors for glaucoma: what do they really mean? Aust J Prim Health. 2011;17:233-9.

3. Shen Y, Zhao J, Yao P, Miao H, Niu L, Wang X, Zhou X. Changes in corneal deformation parameters after lenticule creation and extraction during small incision lenticule extraction (SMILE) procedure. PLoS One. 2014;9:e103893.

4. Kim NR, Kim CY, Kim H, Seong GJ, Lee ES. Comparison of goldmann applanation tonometer, noncontact tonometer, and TonoPen $\mathrm{XL}$ for intraocular pressure measurement in different types of glaucomatous, ocular hypertensive, and normal eyes. Curr Eye Res. 2011;36:295-300.

5. Lee M, Ahn J. Effects of central corneal stromal thickness and epithelial thickness on intraocular pressure using goldmann applanation and noncontact tonometers. PLoS One. 2016:11:e0151868.

6. Kohlhaas M, Boehm AG, Spoerl E, Pürsten A, Grein HJ, Pillunat LE. Effect of central corneal thickness, corneal curvature, and axial length on applanation tonometry. Arch Ophthalmol. 2006;124:471-6.

7. Schallhorn JM, Schallhorn SC, Ou Y. Factors that influence intraocular pressure changes after myopic and hyperopic LASIK and photorefractive keratectomy: a large population study. Ophthalmology. 2015:122:471-9.

8. Uzbek AK, Kamburoglu G, Mahmoud AM, Roberts CJ. Change in biomechanical parameters after flap creation using the Intralase femtosecond laser andsubsequent excimer laser ablation. Curr Eye Res. 2011;36:614-9.

9. Silva TG, Polido JG, Pinheiro MV, Silva AL, Goldbach L, Mascaro VL, Serracarbassa PD, Araújo ME. Application of corrective formula for intraocular pressure changes in patients that underwent LASIK. Arq Bras Oftalmol. 2011;74:102-5.

10. Goldmann H, Schmidt T. Applanation tonometry. Ophthalmologica. 1957; 134:221-42.

11. Bhan A, Browning AC, Shah S, Hamilton R, Dave D, Dua HS. Effect of corneal thickness on intraocular pressuren measurements with the pneumotonometer, Goldmann applanation tonometer and Tono-pen. Invest Ophthalmol Vis Sci. 2002;43:1389-92.

12. Hatami-Marbini H, Rahimi A. Interrelation of hydration, collagen crosslinking treatment, and biomechanical properties of the cornea. Curr Eye Res. 2015;30:1-7.

13. Shen Y, Chen Z, Knorz MC, Li M, Zhao J, Zhou X. Comparison of corneal deformation parameters after SMILE, LASEK, and femtosecond laser-assisted LASIK. J Refract Surg. 2014;30:310-8.

14. Reinstein DZ, Archer TJ, Randleman JB. Mathematical model to compare the relative tensile strength of the cornea after PRK, LASIK, and small incision lenticule extraction. J Refract Surg. 2013;29:454-60.

15. Shah S, Laiquzzaman M, Yeung I, Pan X, Roberts $C$. The use of the ocular response analyser to determine corneal hysteresis in eyes before and after excimer laser refractive surgery. Cont Lens Anterior Eye. 2009;32:123-8.

16. Osman IM, Helaly HA, Abdalla M, Shousha MA. Corneal biomechanical changes in eyes with small incision lenticule extraction and laser assisted in situ keratomileusis. BMC Ophthalmol. 2016;16:123.

17. Osman E. Laser refractive surgery in glaucoma patients. Saudi J Ophthalmol. 2011;25:169-73.

18. Shrivastava A, Madu A, Schultz J. Refractive surgery and the glaucoma patient. Curr Opin Ophthalmol. 2011;22:215-21.

19. Detry-Morel M, Jamart J, Pourjavan S. Evaluation of corneal biomechanical properties with the Reichert ocular response analyzer. Eur J Ophthalmol. 2011;21:138-48

20. Vestergaard AH, Grauslund J, Ivarsen AR, Hjortdal JØ. Central cornea sublayer pachymetry and biomechanical properties after refractive femtosecond lenticule extraction. J Refract Surg. 2014;30:102-8.

21. Cheng AC, Fan D, Tang E, Lam DS. Effect of corneal curvature and corneal thickness on the assessment of intraocular pressure using noncontact tonometry in patients after myopic LASIK surgery. Cornea. 2006;25:26-8.

22. Chen S, Chen D, Wang J, Lu F, Wang Q, Qu J. Changes in ocular response analyzer parameters after LASIK. J Refract Surg. 2010;26:279-88.

23. Aristeidou AP, Labiris G, Katsanos A, Fanariotis M, Foudoulakis NC, Kozobolis VP. Comparison between Pascal dynamic contour tonometer and
Goldmann applanation tonometer after different types of refractive surgery. Graefes Arch Clin Exp Ophthalmol. 2011;249:767-73.

24. Hong J, Yu Z, Jiang C, Zhou X, Liu Z, Sun X, Xu J. Corvis ST Tonometer for Measuring Postoperative IOP in LASIK Patients. Optom Vis Sci. 2015:92:589-95.

25. Kohlhaas M, Spoerl E, Schilde T, Unger G, Wittig C, Pillunat LE. Biomechanical evidence of the distribution of cross-links in corneas treated with riboflavin and ultraviolet A light. J Cataract Refract Surg. 2006;32:279-83.

26. Wang D, Liu M, Chen Y, Zhang X, Xu Y, Wang J, To CH, Liu Q. Differences in the corneal biomechanical changes after SMILE and LASIK. J Refract Surg. 2014;30:702-7.

27. Reinstein DZ, Archer TJ, Gobbe M. Small incision lenticule extraction (SMILE) history, fundamentals of a new refractive surgery technique and clinical outcomes. Eye Vis (Lond). 2014;16:1:3.

28. Chou CY, Jordan CA, McGhee CN, Patel DV. Comparison of intraocular pressure measurement using 4 different instruments following penetrating keratoplasty. Am J Ophthalmol. 2012;153:412-8.

29. Luce DA. Determining in vivo biomechanical properties of the cornea with an ocular response analyzer. J Cataract Refract Surg. 2005;31:156-62.

\section{Submit your next manuscript to BioMed Central and we will help you at every step:}

- We accept pre-submission inquiries

- Our selector tool helps you to find the most relevant journal

- We provide round the clock customer support

- Convenient online submission

- Thorough peer review

- Inclusion in PubMed and all major indexing services

- Maximum visibility for your research

Submit your manuscript at www.biomedcentral.com/submit
Biomed Central 